\title{
Validation of an HPLC Analytical Method for Determination of Biogenic Amines in Agricultural Products and Monitoring of Biogenic Amines in Korean Fermented Agricultural Products
}

\author{
Hyeock Yoon ${ }^{1, \#}$, Jung Hyuck Park ${ }^{1, \#}$, Ari Choi ${ }^{2}$, Han-Joon Hwang ${ }^{1}$ and Jae-Hyung Mah ${ }^{1}$ \\ 'Department of Food and Biotechnology, Korea University, Sejong, Korea \\ ${ }^{2}$ Nutrition Policy \& Promotion Team, Korea Health Industry Development Institute, Chungcheongbuk-do, Korea
}

(Received August 14, 2015; Revised September 7, 2015; Accepted September 10, 2015)

\begin{abstract}
An HPLC analytical method was validated for the quantitative determination of biogenic amines in agricultural products. Four agricultural foods, including apple juice, Juk, corn oil and peanut butter, were selected as food matrices based on their water and fat contents (i.e., non-fatty liquid, non-fatty solid, fatty liquid and fatty solid, respectively). The precision, accuracy, recovery, limit of detection (LOD) and quantification (LOQ) were determined to test the validity of an HPLC procedure for the determination of biogenic amines, including tryptamine, $\beta$-phenylethylamine, putrescine, cadaverine, histamine, tyramine, spermidine and spermine, in each matrix. The LODs and LOQs for the biogenic amines were within the range of $0.01 \sim 0.10 \mathrm{mg} / \mathrm{kg}$ and $0.02 \sim 0.31 \mathrm{mg} / \mathrm{kg}$, respectively. The relative standard deviation (RSD) of intraday for biogenic amine concentrations ranged from 1.86 to $5.95 \%$, whereas the RSD of interday ranged from 2.08 to $5.96 \%$. Of the matrices spiked with biogenic amines, corn oil with tyramine and Juk with putrescine exhibited the least accuracy of $84.85 \%$ and recovery rate of $89.63 \%$, respectively, at the lowest concentration $(10 \mathrm{mg} / \mathrm{kg})$. Therefore, the validation results fulfilled AOAC criteria and recommendations. Subsequently, the method was applied to the analysis of biogenic amines in fermented agricultural products for a total dietary survey in Korea. Although the results revealed that Korean traditional soy sauce and Doenjang contained relatively high levels of histamine, the amounts are of no concern if these fermented agricultural products serve as condiments.
\end{abstract}

Key words: HPLC, Validation, Biogenic amines, Agricultural products

\section{INTRODUCTION}

Biogenic amines are endogenous and indispensable nitrogenous components of living cells, and thereby most food materials, including agricultural, livestock, and fisheries products, contain various types and levels of biogenic amines depending on variety, maturity and cultivation condition (1). In food industry, however, biogenic amines, especially histamine and tyramine, are defined as harmful compounds produced mainly by microbial decarboxylation

Correspondence to: Jae-Hyung Mah, Department of Food and Biotechnology, Korea University, 2511 Sejong-ro, Sejong 339-700, Korea

E-mail: nextbio@korea.ac.kr

"Yoon $\mathrm{H}$ and Park JH contributed equally to this work.

This is an Open-Access article distributed under the terms of the Creative Commons Attribution Non-Commercial License (http:// creativecommons.org/licenses/by-nc/3.0) which permits unrestricted non-commercial use, distribution, and reproduction in any medium, provided the original work is properly cited. of corresponding amino acids (1,2). Fortunately, usual intake of dietary biogenic amines is considered to cause no adverse reactions because human intestinal amine oxidases quickly metabolize and detoxify these compounds. However, vasoactive biogenic amines, such as histamine and tyramine (and probably $\beta$-phenylethylamine), may cause food intoxication if the capacity of amine-metabolizing enzymes, including monoamine oxidase (MAO), diamine oxidase (DAO) and polyamine oxidase (PAO), is over-saturated and/or the metabolic activity is impaired by specific inhibitors, such as phenelzine (3-5). The symptoms of biogenic amine intoxication in human include nausea, respiratory distress, hot flushes, sweating, heart palpitation, headache, a bright red rash, oral burning, and hypo- or hypertension (6). Furthermore, it is noteworthy that the toxicity of biogenic amines can be enhanced by putrefactive biogenic amines such as putrescine and cadaverine (7), and a carcinogenic nitrosamine, N-nitrosopyrrolidine, may be generated from biogenic polyamines, such as spermidine and spermine, in the presence of nitrites (8). Scombroid poison- 
ing is the most frequently observed disease related with histamine in improperly stored fish. Because of this, the US FDA and the European Commission have set the guidance level of $50 \mathrm{mg} / \mathrm{kg}$ and $100 \mathrm{mg} / \mathrm{kg}$ of histamine in fish, respectively $(9,10)$. At present, histamine is the only biogenic amine with regulatory limits.

For the determination of biogenic amines in foods, various analytical methods have been developed to date. For instance, paper chromatography, thin layer chromatography (TLC), gas liquid chromatography (GLC) and high performance liquid chromatography (HPLC) have been reported to isolate and identify biogenic amines and derivatives thereof, although these methods are often somewhat difficult, expensive and time consuming (11). Meanwhile, mass spectrometry (MS) is widely recognized as an accurate and reliable detection technique when coupled with either GC or HPLC. However, this method is not popular yet in developing countries because it is highly expensive and requires technical skills. In this respect, HPLC is still used widely for the quantitation of biogenic amines in foods. HPLC has been used to determine biogenic amines since the late 1970 s, this earlier method has been modified several times. Particularly, Eerola et al. (12) developed modified procedures for the extraction and derivatization of biogenic amines and utilized perchloric acid and dansyl chloride for extraction and derivatization, respectively. Consequently, they achieved a short analysis time (less than $30 \mathrm{~min}$ ), high resolution, and simultaneous detection of 9 biogenic amines in sausages. As far as we know, this was the first simultaneous analytical method for biogenic amines in foods (especially, livestock products) published in AOAC official journal. Later, Ben-Gigirey et al. (13) applied this method to the analysis of biogenic amines in fisheries products. Even though this method has been used widely to quantify biogenic amines in fermented and non-fermented livestock and fisheries products, validation of the method has not been done in agricultural products. In this study, therefore, the HPLC method was validated in terms of accuracy, selectivity, detection limit, quantification limit, linearity and recovery rate, applied to the analysis of biogenic amines in fermented agricultural products.

\section{MATERIALS AND METHODS}

Food matrices and samples. For the evaluation of HPLC analytical method, 4 different agricultural products, including apple juice, Juk (Korean traditional porridge made of rice), corn oil and peanut butter, were selected as food matrices by a research steering committee, which consists of 11 principal investigators involved in a total dietary survey in Korea, based on their water and fat contents (i.e., non-fatty liquid, non-fatty solid, fatty liquid and fatty solid), which commonly affect and interfere with the performance of HPLC analytical methods. The samples were purchased from retail markets in Sejong city in Korea.

Four different types of fermented agricultural products, including soy sauce, Gochujang, Cheonggukjang and Doenjang, were purchased from 18 supermarkets in 9 different metropolitan cities with populations of more than one million in Korea and transported to the preparation laboratory within the day of collection. The collected products were homogenized to form a composite sample of each product type within 2 3 days. The frozen aliquots of composite samples in sealed containers were delivered to analytical laboratory within a day. After arrival, the samples were immediately subjected to analyses of biogenic amines. Thus, in this study, only one composite sample prepared by Korea Heath Industry Development Institute was subject to analysis for each food item.

Preparation of standard stock solution and working solution. All standard chemicals, including histamine dihydrochloride, $\beta$-phenylethylamine hydrochloride, putrescine dihydrochloride, tyramine hydrochloride, cadaverine dihydrochloride, tryptamine, spermine tetrahydrochloride and spermidine trihydrochloride (Sigma Chemical Co., St. Louis, MO, USA), were of analytical grade. Standard stock solutions of biogenic amines were separately prepared at $10,000 \mathrm{mg} / \mathrm{L}$ concentration in distilled water. Working solutions at concentrations of 100 or $1000 \mathrm{mg} / \mathrm{L}$ were prepared by diluting $100 \mu \mathrm{L}$ of $1000 \mu \mathrm{L}$ of each stock solution in distilled water to bring to a final volume of $10 \mathrm{~mL}$.

Extraction of samples for HPLC analysis. Analysis of biogenic amines in the samples of spiked food matrices and fermented agriculture products was carried out based on the procedure of Ben-Gigirey et al. (13). Briefly, $20 \mathrm{~mL}$ of $0.4 \mathrm{M}$ perchloric acid (Sigma) were added to $5 \mathrm{~g}$ of the samples, and the mixture was homogenized using a vortex mixer (Vortex-Genie, Scientific industries, Inc., Bohemia, NY, USA), reacted in a cold chamber at $4^{\circ} \mathrm{C}$ for $2 \mathrm{hr}$, and centrifuged at $3000 \times \mathrm{g}$ at $4^{\circ} \mathrm{C}$ for $10 \mathrm{~min}$. The supernatant was collected, and the residue was extracted again with an equal volume of $0.4 \mathrm{M}$ perchloric acid. Both supernatants were combined, and the final volume was adjusted to $50 \mathrm{~mL}$ with $0.4 \mathrm{M}$ perchloric acid. The extract was filtered through Whatman paper No. 1 (Whatman; GE Healthcare UK Limited, Buckinghamshire, UK).

Derivatization of extracts and standards. Derivatization of biogenic amines was carried out according to the procedures developed by Ben-Gigirey et al. (13). One milliliter of extract or standard solution prepared as above was mixed with $200 \mu \mathrm{L}$ of $2 \mathrm{M}$ sodium hydroxide and $300 \mu \mathrm{L}$ of saturated sodium bicarbonate solution. Two milliliters of a dansyl chloride (Sigma) solution $(10 \mathrm{mg} / \mathrm{mL})$ prepared in acetone were added to the mixture, which was then incubated at $40^{\circ} \mathrm{C}$ for $45 \mathrm{~min}$. Residual dansyl chloride was 
removed by adding $100 \mu \mathrm{L}$ of $25 \%$ ammonium hydroxide. After incubation for $30 \mathrm{~min}$ at $25^{\circ} \mathrm{C}$, the volume of mixture was adjusted with acetonitrile to $5 \mathrm{~mL}$. Finally, the mixture was centrifuged at $3000 \times \mathrm{g}$ for $5 \mathrm{~min}$, and the supernatant was filtered through $0.2 \mu \mathrm{m}$-pore-size filters (Millipore Co., Bedford, MA, USA). The filtered supernatant was kept at $-25^{\circ} \mathrm{C}$ until assayed by HPLC.

Chromatographic separations. Chromatographic separation of biogenic amines was carried out according to the procedures developed by Ben-Gigirey et al. (13) with minor modifications. An HPLC unit (YL 9100, Young Lin Instrument, Co., Anyang, Korea), equipped with a UV-Vis detector (YL 9120, Young Lin) and Autochro-3000 software (Young Lin) was employed. A Nova-Pak $\mathrm{C}_{18} 4 \mu \mathrm{m}$ column (150 mm $\times 3.9 \mathrm{~mm}$, Waters, Milford, MA, USA) was used for the separation of biogenic amines, and the samples were eluted with a step gradient of ammonium acetate $(0.1 \mathrm{M}$; Sigma; solvent A) and acetonitrile (SK chemicals, Ulsan, Korea; solvent B) as the mobile phases at the flow rate of $1 \mathrm{~mL} / \mathrm{min}$. The program was set for a linear gradient starting from $50 \%$ of solvent B to reach $90 \%$ of the solvent at $19 \mathrm{~min}$. The sample volume injected was $10 \mu \mathrm{L}$ and monitored at $254 \mathrm{~nm}$.

Spiking recovery test. The recovery test was performed by spiking food matrices with eight biogenic amines at three fortification levels of 10,100 and $500 \mathrm{mg} / \mathrm{kg}$. The reference spiked samples were pretreated and analyzed as described above. Recovery rate was calculated by comparing the amount of each biogenic amine detected in the spiked sample with the amount of each standard material added to sample. The analysis was conducted in quintuplicate.

Validation parameters. The method for the quantitation of biogenic amines in agricultural products was validated in terms of the analytical parameters of selectivity, linearity, precision, accuracy, recovery, limit of detection (LOD) and limit of quantification (LOQ) following conventional protocols from international guidelines $(14,15)$. The analysis was conducted in quintuplicate.

\section{RESULTS AND DISCUSSION}

Specificity. The specificity of this method was validated by comparing original samples (without spiking with standard materials) with spiked samples with standard material and identifying peaks for each of biogenic amines (Fig. 1). At first, the levels of biogenic amines in four different food matrices were evaluated to determine if the concentrations of biogenic amines in non-spiked matrices are adequately low for spiking experiments. Cadaverine and $\beta$ phenylethylamine were not detected in all food matrices,

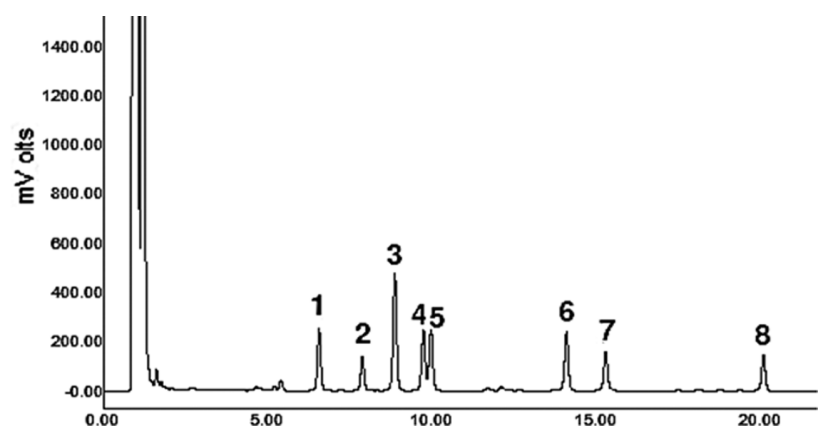

Fig. 1. Typical HPLC chromatogram of dansyl-derivatized biogenic amines. 1, tryptamine; 2 , $\beta$-phenylethylamine; 3 , putrescine; 4 , cadaverine; 5,histamine; 6 , tyramine; 7 , spermidine; 8 , spermine.

whereas tryptamine and putrescine were detected in all food matrices. Spermidine and spermine were detected in all food matrices except for corn oil. Tyramine was detected in both apple juice and peanut butter, while histamine was detected only in apple juice. The highest levels of spermidine and spermine were $26.12 \pm 5.58 \mathrm{mg} / \mathrm{kg}$ and $20.07 \pm$ $0.53 \mathrm{mg} / \mathrm{kg}$ detected in peanut butter, respectively. The other biogenic amines were less than $6 \mathrm{mg} / \mathrm{kg}$ in all food matrices. Secondly, a constant concentration of standard materials was spiked into food matrices. As shown in Fig. 1 , there appeared no interference between peaks of biogenic amines. It is worth mentioning that, however, there may be interference between peaks of cadaverine and histamine if column performance deteriorates.

Linearity, detection limit and quantification limit. The linearity test was carried out at six concentration levels of biogenic amines: 25, 50, 100, 250, 500 and $1000 \mathrm{mg} / \mathrm{kg}$. The analysis was conducted in quintuplicate. Linear calibration curves were plotted between the peak area and the corresponding concentration of respective biogenic amines, and the resulting correlation coefficients for eight biogenic amines in the calibration range were over 0.99 , regardless of food matrices.

The determination of limit of detection (LOD) and limit of quantification (LOQ) was carried out by injecting the standard mixtures of eight biogenic amines at smaller concentrations (i.g., $10 \mathrm{mg} / \mathrm{kg}$ ) five times, and the LOD was taken at a signal to noise ratio of 3 , while the LOQ was taken at a signal to noise ratio of 10 . As shown in Table 1, the resulting LODs for eight biogenic amines ranged from 0.01 to $0.10 \mathrm{mg} / \mathrm{kg}$ and the LOQs ranged from 0.02 to 0.31 $\mathrm{mg} / \mathrm{kg}$.

Precision. The repeatability test for peak area was carried out by injecting the standard mixtures of eight biogenic amines at the concentrations of 10, 100 and $500 \mathrm{mg} /$ $\mathrm{kg}$ five times a day. As shown in Table 2, the relative stan- 
Table 1. LOD and LOQ values of validated HPLC method for biogenic amines in food matrices

\begin{tabular}{ccccccccccc}
\hline \hline \multirow{2}{*}{ Matrix } & \multicolumn{7}{c}{ LODs and LOQs of biogenic amines (mg/kg) } \\
\cline { 3 - 10 } & & Trp ${ }^{1)}$ & $\beta$-phe & Put & Cad & His & Tyr & Spd & Spm \\
\hline Apple juice & LOD & 0.06 & 0.08 & 0.08 & 0.05 & 0.06 & 0.07 & 0.08 & 0.10 \\
(Non fatty liquid group) & LOQ & 0.17 & 0.25 & 0.26 & 0.15 & 0.20 & 0.20 & 0.24 & 0.31 \\
\hline Juk & LOD & 0.06 & 0.03 & 0.03 & 0.02 & 0.01 & 0.02 & 0.09 & 0.08 \\
(Non fatty solid group) & LOQ & 0.17 & 0.10 & 0.10 & 0.06 & 0.02 & 0.06 & 0.28 & 0.24 \\
\hline Corn oil & LOD & 0.03 & 0.06 & 0.03 & 0.03 & 0.06 & 0.01 & 0.08 & 0.07 \\
(Fatty liquid group) & LOQ & 0.10 & 0.18 & 0.11 & 0.10 & 0.18 & 0.02 & 0.24 & 0.21 \\
\hline Peanut butter & LOD & 0.02 & 0.02 & 0.05 & 0.06 & 0.07 & 0.04 & 0.02 & 0.06 \\
(Fatty solid group) & LOQ & 0.05 & 0.06 & 0.15 & 0.19 & 0.22 & 0.13 & 0.06 & 0.19 \\
\hline
\end{tabular}

${ }^{1)}$ Trp, tryptamine; Phe, $\beta$-phenylethylamine; Put, putrescine; Cad, cadaverine; His, histamine; Tyr, tyramine; Spd, spermidine; Spm, spermine.

Table 2. The intra- and interday precision of validated HPLC method for biogenic amines in food matrices

\begin{tabular}{|c|c|c|c|c|c|c|c|c|c|c|c|c|c|c|c|c|c|c|}
\hline \multirow{2}{*}{ Matrix } & \multirow{2}{*}{$\begin{array}{l}\text { Concentration } \\
(\mathrm{mg} / \mathrm{kg})\end{array}$} & \multicolumn{8}{|c|}{ Intraday $(\mathrm{RSD}, \%), \mathrm{n}=5$} & \multicolumn{8}{|c|}{ Interday (RSD, \%), $\mathrm{n}=5$} & \multirow{2}{*}{$\begin{array}{c}\text { AOAC } \\
(\mathrm{RSD}, \%)^{2)}\end{array}$} \\
\hline & & $\operatorname{Trp}^{1)}$ & $\beta$-phe & Put & $\mathrm{Cad}$ & His & Tyr & Spd & Spm & $\operatorname{Trp}^{1)}$ & $\beta$-phe & Put & $\mathrm{Cad}$ & His & Tyr & Spd & Spm & \\
\hline \multirow{3}{*}{$\begin{array}{l}\text { Apple juice } \\
\text { (Non fatty } \\
\text { liquid group) }\end{array}$} & 10 & 4.58 & 5.44 & 3.57 & 2.63 & 5.90 & 4.20 & 4.19 & & 422 & & 3.57 & 4.57 & 5.15 & 5.41 & 4.15 & 5.40 & \\
\hline & & 66 & 3.80 & 3.35 & 3.59 & 2.39 & 2.82 & 2.52 & 2.84 & 3.92 & 3.8 & 3.35 & 3.68 & 3.27 & 3.22 & 3.94 & & \\
\hline & & 3.84 & 2.08 & 2.57 & 3.73 & 3.46 & 2.45 & 3.32 & 3.00 & 2.78 & 2.08 & 2.57 & 3.84 & 3.14 & 2.68 & 3.35 & 3.39 & \\
\hline \multirow{3}{*}{$\begin{array}{c}J u k \\
\text { (Non fatty } \\
\text { solid group) }\end{array}$} & 10 & 3.70 & 5.21 & 5.03 & 4.29 & 5.06 & 5.95 & 3.37 & 3.01 & 4.61 & 3.24 & 5.03 & 2.47 & 5.06 & 5.95 & 3.37 & 4.96 & $<6 \%$ \\
\hline & 100 & 69 & 3.59 & 3.28 & 2.48 & 3.65 & 3.45 & 3.18 & 2.58 & 3.40 & 3.59 & 3.28 & 2.39 & 3.65 & 3.45 & 3.18 & 3.50 & \\
\hline & 500 & 2.75 & 3.49 & 2.12 & 3.63 & 3.65 & 3.90 & 2.85 & 3.81 & 2.23 & 3.49 & 3.78 & 3.73 & 3.65 & 3.90 & 2.85 & 3.63 & $<4 \%$ \\
\hline \multirow{3}{*}{$\begin{array}{c}\text { Corn oil } \\
\text { (Fatty liquid } \\
\text { group) } \\
\end{array}$} & 10 & 4.80 & 2.58 & 2.89 & 2.74 & 2.31 & 1.86 & 4.09 & 2.22 & 4.18 & 3.11 & 3.23 & 3.78 & 3.32 & 3.06 & 4.09 & 4.5 & $<6 \%$ \\
\hline & 100 & 2.82 & 3.17 & 3.56 & 2.73 & 3.24 & 2.79 & 2.16 & 2.32 & 2.90 & 3.17 & 3.58 & 2.73 & 3.29 & 2.79 & 2.16 & 2.32 & $<4 \%$ \\
\hline & 500 & 2.70 & 2.73 & 2.25 & 2.40 & 1.88 & 2.19 & 3.17 & 2.20 & 2.90 & 2.73 & 2.37 & 2.40 & 3.19 & 2.64 & 3.17 & 2.75 & $<4 \%$ \\
\hline \multirow{3}{*}{$\begin{array}{l}\text { Peanut butter } \\
\text { (Fatty solid } \\
\text { group) }\end{array}$} & 10 & 4.66 & 5.41 & 3.87 & 4.84 & 3.15 & 2.19 & 4.55 & 3.61 & 5.47 & 5.90 & 3.68 & 3.38 & 3.11 & 5.96 & 4.59 & 5.31 & $<6 \%$ \\
\hline & 100 & 2.56 & 3.53 & 2.11 & 3.48 & 2.88 & 2.48 & 2.85 & 3.71 & 3.36 & 3.14 & 3.17 & 3.48 & 2.88 & 2.44 & 3.11 & 3.94 & $<4 \%$ \\
\hline & 500 & 3.89 & 3.34 & 2.97 & 3.02 & 3.28 & 3.20 & 3.29 & 2.47 & 3.02 & 3.34 & 2.61 & 3.02 & 3.28 & 3.29 & 3.75 & 3.55 & $<4 \%$ \\
\hline
\end{tabular}

${ }^{11}$ Trp, tryptamine; Phe, $\beta$-phenylethylamine; Put, putrescine; Cad, cadaverine; His, histamine; Tyr, tyramine; Spd, spermidine; Spm, spermine.

${ }^{2)} \mathrm{AOAC}$ criteria.

dard deviation (RSD) of intraday precision for peak area ranged from 1.86 to $5.95 \%$. Meanwhile, the reproducibility test was performed by injecting the standard mixtures of eight biogenic amines at the concentrations of 10,100 and $500 \mathrm{mg} / \mathrm{kg}$, which was done daily for 5 days. As shown in Table 2, the RSD of interday precision for peak area ranged from 2.08 to $5.96 \%$. Taken together, the precision of method is within the expected range (14).

Accuracy and recovery rate. The accuracy and recovery test was performed to validate the accuracy of the method by spiking four different food matrices with biogenic amines at three fortification levels of 10, 100 and 500 $\mathrm{mg} / \mathrm{kg}$. Accuracy was calculated by comparing the amount of each biogenic amine detected in the spiked food matrix with the amount of internal standard detected in the food matrix. Recovery rate was calculated by comparing the amount of each biogenic amine detected in the spiked food matrix with the amount of each standard material added to food matrix. The analysis was conducted in quintuplicate, and the results of accuracy and recovery studies were given in Table 3 and Table 4, respectively. The accuracy ranged from $84.85 \%$ to $109.97 \%$, whereas the recovery rate ranged from $89.63 \%$ to $107.74 \%$. Therefore, it is clear that the accuracy and recovery of the method for the determination of biogenic amines in the agricultural food matrices are within the expected ranges.

\section{Biogenic amines in fermented agricultural products.}

Aliquots of the composite samples prepared individually from four representative types of Korean fermented agricultural products, including soy sauce, which is subdivided into Korean traditional soy sauce and brewed soy sauce, Gochujang, Cheonggukjang and Doenjang, were analyzed by the validated HPLC. As shown in Table 5, $\beta$-phenylethylamine, putrescine, cadaverine, histamine and tyramine were detected in both types of soy sauces, whereas tryptamine and spermine were not detected in the same aliquots. Particularly, the levels of $\beta$-phenylethylamine, putrescine, cadaverine and tyramine were higher in brewed than in 
Table 3. Accuracy of validated HPLC method for biogenic amines in food matrices

\begin{tabular}{|c|c|c|c|c|c|c|c|c|c|c|}
\hline \multirow{2}{*}{ Matrix } & \multirow{2}{*}{$\begin{array}{l}\text { Concentration } \\
(\mathrm{mg} / \mathrm{kg})\end{array}$} & \multicolumn{8}{|c|}{ Accuracy $(\%), n=5$} & \multirow{2}{*}{$\begin{array}{l}\text { AOAC } \\
(\%)^{2)}\end{array}$} \\
\hline & & $\operatorname{Trp}^{1)}$ & $\beta$-phe & Put & $\mathrm{Cad}$ & His & Tyr & Spd & Spm & \\
\hline \multirow{3}{*}{$\begin{array}{c}\text { Apple juice } \\
\text { (Non fatty liquid group) }\end{array}$} & 10 & 89.85 & 94.62 & 101.90 & 92.42 & 100.90 & 94.54 & 96.83 & 102.89 & $80-115$ \\
\hline & 100 & 95.84 & 87.87 & 94.20 & 98.35 & 91.13 & 98.67 & 100.55 & 101.81 & $85-110$ \\
\hline & 500 & 93.92 & 94.83 & 99.93 & 98.31 & 96.85 & 94.89 & 92.54 & 98.31 & $85-110$ \\
\hline \multirow{3}{*}{$\begin{array}{c}J u k \\
\text { (Non fatty solid group) }\end{array}$} & 10 & 108.27 & 102.36 & 94.67 & 109.58 & 101.89 & 102.34 & 109.48 & 104.44 & $80-115$ \\
\hline & 100 & 101.05 & 98.39 & 109.97 & 102.11 & 104.77 & 101.92 & 105.95 & 102.44 & $85-110$ \\
\hline & 500 & 94.21 & 96.35 & 100.81 & 101.81 & 98.21 & 95.92 & 99.11 & 95.09 & $85-110$ \\
\hline \multirow{3}{*}{$\begin{array}{c}\text { Corn oil } \\
\text { (Fatty liquid group) }\end{array}$} & 10 & 94.05 & 85.97 & 90.49 & 86.57 & 93.88 & 84.85 & 86.60 & 92.79 & $80-115$ \\
\hline & 100 & 90.34 & 90.83 & 95.87 & 94.10 & 97.54 & 89.12 & 97.63 & 87.90 & $85-110$ \\
\hline & 500 & 93.05 & 94.83 & 99.13 & 94.41 & 96.14 & 100.23 & 91.83 & 100.97 & $85-110$ \\
\hline \multirow{3}{*}{$\begin{array}{c}\text { Peanut butter } \\
\text { (Fatty solid group) }\end{array}$} & 10 & 93.70 & 98.27 & 99.71 & 99.66 & 97.55 & 89.87 & 93.85 & 90.29 & $80-115$ \\
\hline & 100 & 96.32 & 91.83 & 96.24 & 102.24 & 100.60 & 97.86 & 103.71 & 91.83 & $85-110$ \\
\hline & 500 & 101.75 & 93.32 & 97.60 & 103.70 & 101.77 & 91.19 & 102.06 & 103.34 & $85-110$ \\
\hline
\end{tabular}

${ }^{11}$ Trp, tryptamine; Phe, $\beta$-phenylethylamine; Put, putrescine; Cad, cadaverine; His, histamine; Tyr, tyramine; Spd, spermidine; Spm, spermine. ${ }^{2)} \mathrm{AOAC}$ criteria.

Table 4. Recovery rate of validated HPLC method for biogenic amines in food matrices

\begin{tabular}{|c|c|c|c|c|c|c|c|c|c|c|}
\hline \multirow{2}{*}{ Matrix } & \multirow{2}{*}{$\begin{array}{l}\text { Concentration } \\
(\mathrm{mg} / \mathrm{kg})\end{array}$} & \multicolumn{8}{|c|}{ Recovery (\%), $\mathrm{n}=5$} & \multirow{2}{*}{$\begin{array}{l}\text { AOAC } \\
(\%)^{2)}\end{array}$} \\
\hline & & $\operatorname{Trp}^{1)}$ & $\beta$-phe & Put & $\mathrm{Cad}$ & His & Tyr & Spd & Spm & \\
\hline \multirow{3}{*}{$\begin{array}{c}\text { Apple juice } \\
\text { (Non fatty liquid group) }\end{array}$} & 10 & 94.78 & 96.21 & 103.62 & 93.98 & 102.60 & 96.13 & 98.46 & 104.62 & $80-115$ \\
\hline & 100 & 100.73 & 92.35 & 99.01 & 103.37 & 95.78 & 103.70 & 105.68 & 107.01 & $85-110$ \\
\hline & 500 & 97.49 & 98.44 & 103.73 & 102.05 & 100.54 & 98.50 & 96.06 & 102.05 & $85-110$ \\
\hline \multirow{3}{*}{$\begin{array}{c}J u k \\
\text { (Non fatty solid group) }\end{array}$} & 10 & 102.50 & 96.90 & 89.63 & 103.75 & 96.46 & 96.89 & 103.65 & 98.87 & $80-115$ \\
\hline & 100 & 97.61 & 95.04 & 106.23 & 98.64 & 101.21 & 98.45 & 102.35 & 98.96 & $85-110$ \\
\hline & 500 & 95.50 & 97.66 & 102.18 & 103.20 & 99.55 & 97.23 & 100.45 & 96.39 & $85-110$ \\
\hline \multirow{3}{*}{$\begin{array}{c}\text { Corn oil } \\
\text { (Fatty liquid group) }\end{array}$} & 10 & 106.72 & 97.55 & 102.68 & 98.24 & 106.53 & 96.28 & 98.27 & 105.29 & $80-115$ \\
\hline & 100 & 97.12 & 97.66 & 103.07 & 101.17 & 104.87 & 95.81 & 104.97 & 94.51 & $85-110$ \\
\hline & 500 & 96.49 & 98.33 & 102.79 & 97.89 & 99.68 & 103.93 & 95.22 & 104.69 & $85-110$ \\
\hline \multirow{3}{*}{$\begin{array}{c}\text { Peanut butter } \\
\text { (Fatty solid group) }\end{array}$} & 10 & 97.91 & 102.68 & 104.19 & 104.14 & 101.93 & 93.90 & 98.07 & 94.35 & $80-115$ \\
\hline & 100 & 99.80 & 95.15 & 99.73 & 105.94 & 104.24 & 101.41 & 107.46 & 95.16 & $85-110$ \\
\hline & 500 & 105.71 & 96.96 & 101.41 & 107.74 & 105.73 & 94.74 & 106.04 & 107.37 & $85-110$ \\
\hline
\end{tabular}

${ }^{1)}$ Trp, tryptamine; Phe, $\beta$-phenylethylamine; Put, putrescine; Cad, cadaverine; His, histamine; Tyr, tyramine; Spd, spermidine; Spm, spermine. ${ }^{2)} \mathrm{AOAC}$ criteria.

Table 5. Levels of biogenic amines determined in fermented agricultural products

\begin{tabular}{|c|c|c|c|c|c|c|c|c|}
\hline \multirow{2}{*}{ Samples } & \multicolumn{8}{|c|}{ Biogenic amines $(\mathrm{mg} / \mathrm{kg})^{1)}$} \\
\hline & $\operatorname{Trp}^{2)}$ & Phe & Put & Cad & His & Tyr & Spd & Spm \\
\hline Korean fermented soy sauce & $\mathrm{N}^{3)}$ & $6.31 \pm 2.84$ & $1.40 \pm 1.00$ & $3.79 \pm 2.25$ & $118.83 \pm 15.20$ & $5.33 \pm 1.21$ & $1.04 \pm 0.31$ & $\mathrm{~N}$ \\
\hline Brewed soy sauce & $\mathrm{N}$ & $17.95 \pm 3.35$ & $5.37 \pm 1.01$ & $25.22 \pm 3.10$ & $59.77 \pm 16.16$ & $40.32 \pm 13.28$ & $\mathrm{~N}$ & $\mathrm{~N}$ \\
\hline Gochujang & $44.96 \pm 0.60$ & $1.81 \pm 0.09$ & $9.42 \pm 7.30$ & $\mathrm{~N}$ & $8.67 \pm 0.41$ & $1.08 \pm 0.61$ & $2.24 \pm 0.14$ & $3.04 \pm 0.67$ \\
\hline Doenjang & $61.15 \pm 6.46$ & $27.77 \pm 1.22$ & $99.48 \pm 4.23$ & $\mathrm{~N}$ & $206.57 \pm 4.18$ & $27.16 \pm 2.80$ & $1.63 \pm 0.50$ & $12.36 \pm 0.34$ \\
\hline Cheonggukjang & $39.60 \pm 1.73$ & $15.42 \pm 1.05$ & $26.67 \pm 2.68$ & $5.40 \pm 0.14$ & $13.91 \pm 1.29$ & $20.68 \pm 1.86$ & $46.95 \pm 1.85$ & $4.11 \pm 0.71$ \\
\hline
\end{tabular}

Korean traditional soy sauce, while the level of histamine $(118.83 \pm 15.20 \mathrm{mg} / \mathrm{kg})$ was higher in Korean traditional soy sauce. These results are in strong agreement with the previous study in which $3.9 \sim 398.8 \mathrm{mg} / \mathrm{kg}$ and $13.8 \sim 229.8 \mathrm{mg} /$ $\mathrm{kg}$ of histamine were detected in Korean traditional soy sauce and brewed soy sauce, respectively (16). 
Gochujang and Doenjang contained all biogenic amines, except for cadaverine, but showed different levels of biogenic amines, although both fermented agricultural products are produced from Meju, a brick-shaped fermented soybean starter, through fungal fermentation. The levels of all detected biogenic amines, except for spermidine, were much higher in Doenjang than in Gochujang, which might be due to the difference in raw materials and procedures used for the production of fermented agricultural products. It is also worth emphasizing that, while Doenjang contained the highest level of histamine $(206.57 \pm 4.18 \mathrm{mg} / \mathrm{kg})$, Gochujang had the lowest level of histamine $(8.67 \pm 0.41$ $\mathrm{mg} / \mathrm{kg}$ ) among the fermented agricultural products analyzed in this study. This finding is in strong accordance with a recent study in which $71.1 \sim 382.4 \mathrm{mg} / \mathrm{kg}$ and $2.2 \sim 59.0$ $\mathrm{mg} / \mathrm{kg}$ of histamine were detected in Doenjang and Gochujang, respectively (17).

In Cheonggukjang, a short-term fermented soybean product, all biogenic amines analyzed were detected, but their levels were less than $50 \mathrm{mg} / \mathrm{kg}$, respectively. Regarding the levels of biogenic amines in Cheonggukjang, Han et al. (18) reported that putrescine and tyramine, which were relatively higher levels than those of the other biogenic amines, were within the range of $4.7 \sim 148.5 \mathrm{mg} / \mathrm{kg}$ and $4.2 \sim 483.1$ $\mathrm{mg} / \mathrm{kg}$, respectively. Considering the ranges of biogenic amine levels in their study, it appears insignificant differences in most biogenic amine levels between the previous and present studies. However, taken together, it should not be overlooked that the amounts of several biogenic amines, especially tyramine, may be occasionally quite high in Cheonggukjang. Indeed, Ko et al. (19) reported that $1913.51 \mathrm{mg} / \mathrm{kg}$ of tyramine was detected in a commercial product.

In summary, an HPLC method was validated for the quantitative determination of biogenic amines in agricultural products, and the validation results fulfilled AOAC and/or FDA criteria and recommendations. Subsequently, the method was applied to the analysis of biogenic amines in composite samples of fermented agricultural products. Consequently, only histamine levels in Korean traditional soy sauce and Doenjang were considerably high. To reduce the risk of biogenic amines in fermented agricultural products, therefore, it is necessary to persistently monitor and substantially reduce biogenic amines, especially histamine, in the products, although the practical intake of biogenic amines could be considered low if these fermented agricultural products serve as condiments.

\section{ACKNOWLEDGEMENTS}

This research was supported by a grant (13162KFDA049) to Jae-Hyung Mah from the Ministry of Food and Drug Safety, Republic of Korea. The authors thank Prof. Han-Joon Hwang's graduate students for sharing their data on LOD and LOQ values.

\section{REFERENCES}

1. Halász, A., Baráth, Á., Simon-Sarkadi, L. and Holzapfel, W. (1994) Biogenic amines and their production by microorganisms in food. Trends Food Sci. Technol., 5, 42-49.

2. ten Brink, B., Damirik, C., Joosten, H.M. and Huis in't Veld, J.H. (1990) Occurrence and formation of biologically active amines in foods. Int. J. Food Microbiol., 11, 73-84.

3. Joosten, H. and Nuñez, M. (1996) Prevention of histamine formation in cheese by bacteriocin-producing lactic acid bacteria. Appl. Environ. Microbiol., 62, 1178-1181.

4. Taylor, S.L., Guthertz, L.S., Leatherwood, M., Tillman, F. and Lieber, E.R. (1978) Histamine production by foodborne bacterial species. J. Food Saf., 1, 173-187.

5. Mah, J.H. (2015) Fermented soybean foods: Significance of biogenic amines. Austin J. Nutr. Food Sci., 3, 1058.

6. Rice, S.L., Eitenmiller, R.R. and Koehler, P.E. (1976) Biologically active amines in foods: a review. J. Milk Food Technol., 39, 353-358.

7. Stratton, J.E., Hutkins, R.W. and Taylor, S.L. (1991) Biogenic amines in cheese and other fermented foods: a review. J. Food Prot., 54, 460-470.

8. Smith, T.A. (1980). Amines in food. Food Chem., 6, 169-200.

9. Food and Drug Administration (FDA). (2011) Fish and fishery products hazards and controls guidance (4th edition), Center for Food Safety and Applied Nutrition, Rockville, MD, USA, pp. 1-468.

10. European Commission (EC). (2005) Commission regulation (EC) No. 2073/2005 of 15th November 2005 on microbiological criteria for Foodstuffs. Off. J. Eur. Union, L338, 1-25.

11. Valls, J.E., Bello, R.A. and Kodaira, M.S. (1999) Validation of liquid chromatography analysis of biogenic amines in canned fish products. J. Aquat. Food Prod. Technol., 8, 79-91.

12. Eerola, S., Hinkkanen, R., Lindfors, E. and Hirvi, T. (1993) Liquid chromatographic determination of biogenic amines in dry sausages. J. AOAC Int., 76, 575-577.

13. Ben-Gigirey, B., Vieites Baptista de Sousa, J.M., Villa, T.G. and Barros-Velazquez, J. (1998) Changes in biogenic amines and microbiological analysis in albacore (Thunnus alalunga) muscle during frozen storage. J. Food Prot., 61, 608-615.

14. Association of Official Analytical Chemists (AOAC). (2002) AOAC Guidelines for single laboratory validation of chemical methods for dietary supplements and botanicals, Association of Official Analytical Chemists, Gaithersburg, MD, USA, pp. 1-38.

15. Food and Drug Administration (FDA). (2012) Guidelines for the Validation of Chemical Methods for the FDA Foods Program. Available from: http://www.fda.gov/downloads/ScienceResearch/FieldScience/UCM298730.pdf. Accessed July 30, 2015.

16. Cho, T.Y., Han, G.H., Bahn, K.N., Son, Y.W., Jang, M.R., Lee, C.H., Kim, S.H., Kim, D.B. and Kim, S.B. (2006) Evaluation of biogenic amines in Korean commercial fermented foods. Korean J. Food Sci. Technol., 38, 730-737.

17. Kim, T.K., Lee, J.I., Kim, J.H., Mah, J.H., Hwang, H.J. and Kim, Y.W. (2011) Comparison of ELISA and HPLC methods for the determination of biogenic amines in commercial Doen- 
jang and Gochujang. Food Sci. Biotechnol., 20, 1747-1750.

18. Han, G.H., Cho, T.Y., Yoo, M.S., Kim, C.S., Kim, J.M., Kim, H.A., Kim, M.O., Kim, S.C., Lee, S.A., Ko, Y.S., Kim, S.H. and Kim, D.B. (2007) Biogenic amines formation and content in fermented soybean paste (Cheonggukjang). Korean J. Food
Sci. Technol., 39, 541-545.

19. Ko, Y.J., Son, Y.H., Kim, E.J., Seol, H.G., Lee, G.R., Kim, D.H. and Ryu, C.H. (2012) Quality properties of commercial Chungkukjang in Korea. J. Agric. Life Sci., 46, 1-11. 